commonly used as a diagnostic agent for the determination of plasma volume..$^{5}$

The reason for inhibition of the sodium nitroprusside response by gentian violet is unclear. Gentian violet is metabolized to a reactive intermediate or free radical that could act at the vascular smooth muscle to inhibit the response. However, this is unlikely inasmuch as this mechanism would also interfere with the acetylcholinemediated vasodilation. A more plausible explanation would be the formation of a reactive intermediate that interacts directly with the sodium nitroprusside molecule.

In conclusion, although methylene blue has been used as a marker dye, our studies suggest that it is inappropriate for marking vascular grafts. Evans blue did not adversely affect vasodilation to any agent and thus could be used as an alternative to methylene blue without fear of affecting graft reactivity. Gentian violet also appears to be a better alternate to methylene blue. However, we did observe a decrease in endothelium-independent vasodilation, a factor that should be considered when this agent is used.

\section{REFERENCES}

1. Barber DA, Rubin JW, Zumbro GL, Tackett RL. The use of methylene blue as an extravascular surgical marker impairs vascular responses of human saphenous veins. J Thorac Cardiovasc Surg 1995;109:21-9.

2. Ignarro LJ, Burke TM, Wood KS, Wolin MS, Kadowitz PJ. Association between cyclic GMP accumulation and acetylcholine-elicited relaxation in bovine intrapulmonary artery. J Pharmacol Exp Ther 1984;228:682-90.

3. Marshall JJ, Wei EP, Lontos HA. Independent blockade of cerebral vasodilation from acetylcholine and nitric oxide. Am J Physiol 1988;255:H847-55.

4. Wakelin LPG, Adams A, Hunter C, Waring MJ. Interactions of crystal violet with nucleic acids. Biochemistry 1981;20:577987.

5. Windholz M, Budavari S, Blumetti RF, Otterbein ES, editors. Evans blue. In The Merck index, 10th ed. Rahway (NJ): Merck \& Co, 1983:3855.

\title{
EROSION OF INLET CANNULA OF LEFT VENTRICULAR ASSIST DEVICE MANIFESTED AS INNOCUOUS BLEEDING IN STABLE PATIENT: LESSONS LEARNED IN PREVENTION OF CATASTROPHIC CONSEQUENCES
}

\author{
Sanjay M. Mehta, MD, and Walter E. Pae, Jr., MD, Hershey, Pa.
}

We present the case of a patient who underwent implantation of a left ventricular assist device (LVAD) as a bridge to transplantation and subsequently had disruption of the Dacron inflow graft of the pump. Surgical investigation at the development of expanding hematoma and drive line bleeding resulted in entrainment of air into the pump, massive air embolus, and subsequent death of the patient. We believe that this case demonstrates the need for angiographic definition of bleeding associated with a completely implanted LVAD before surgical exploration, as well as specific surgical strategies to avoid air embolus.

A 64-year-old man was admitted to our institution with

From the Divisions of Cardiothoracic Surgery, Department of Surgery, University Hospital-Children's Hospital, The Pennsylvania State University, The Milton S. Hershey Medical Center, Hershey, Pa.

Received for publication Dec. 4, 1995; accepted for publication Dec. 13, 1995.

Address for reprints: Sanjay M. Mehta, MD, Department of Surgery, The Milton S. Hershey Medical Center, P.O. Box 850, Hershey, PA 17003.

J Thorac Cardiovasc Surg 1996;112:544-5

Copyright $(\mathcal{O} 1996$ by Mosby-Year Book, Inc.

$0022-5223 / 96 \$ 5.00+0 \quad \mathbf{1 2 / 5 4 / 7 1 1 7 1}$ a history of progressive cardiac failure. He had had aortic valve replacement with a porcine prosthesis and implantation of a pacemaker 7 years before this admission. An extensive evaluation indicated end-stage dilated cardiomyopathy. The patient was activated on the waiting list for cardiac transplantation. Despite a regimen of dopamine, dobutamine, amrinone, and intravenous diuretics, the patient had progressive symptoms of cardiac failure. An intraaortic balloon pump was inserted, with only marginal improvement in hemodynamics. Despite this aggressive conventional management, the patient had progressive deterioration and thus underwent preperitoneal implantation $^{1,2}$ of the Thermo Cardiosystems Incorporated (TCI) Heartmate LVAD (Woburn, Mass.) 2 months after admission. The initial postoperative course was uneventful except for transient failure of the right side of the heart, responsive to dopamine, during the first postoperative week and thoracentesis on two occasions in the early postoperative course for recurrent left pleural effusion with drainage on each occasion of approximately $1 \mathrm{~L}$ of serous fluid. On postoperative day 32 the patient was evaluated on an emergency basis for brisk bleeding around the drive line site, and physical examination confirmed an expanding collection of fluid within the preperitoneal implantation pocket. The patient was promptly taken to the operating room for suspected bleeding within the preperitoneal pocket. The preperito- 


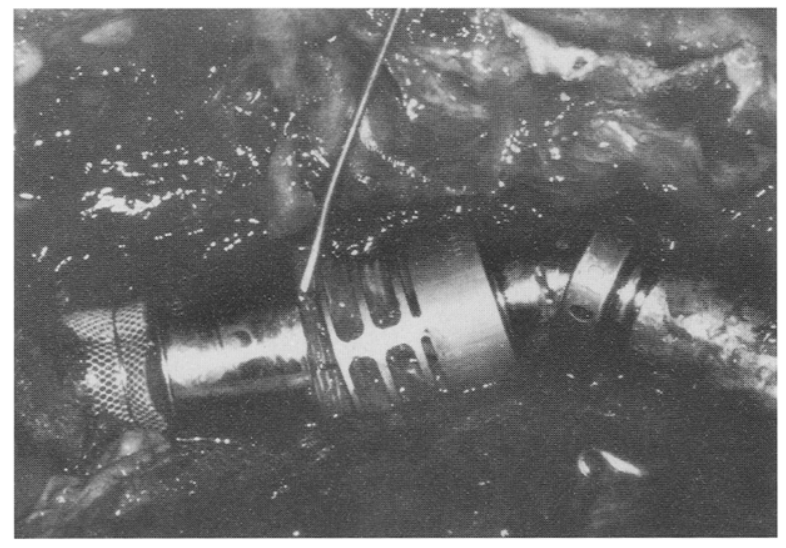

Fig. 1. Probe shows site of erosion along inlet cannula owing to displacement of overlying protective cage.

neal pocket was opened and noted to have a collection of approximately $2 \mathrm{~L}$ of dark clotted blood. This collection was removed to identify the underlying bleeding site, which was quickly identified to be a defect in the inlet cannula of the pump. The patient's chest was promptly opened and cardiopulmonary bypass initiated. The pump was stopped and the cannula evaluated. Unfortunately, despite rapid and aggressive intervention, the patient's heart, aorta, and pump were noted to be filled with entrained air. The patient died shortly thereafter in the operating room.

An autopsy subsequently revealed that the cage support had eroded through and resulted in a $2 \mathrm{~cm}$ laceration in the Dacron inlet graft (Fig. 1). This laceration was located at the level of the diaphragm, with consequent subdiaphragmatic blood collection, likely the source of the recurrent serous pleural effusions on that side. No other abnormalities associated with the pump or its implantation were noted at that time.

To our knowledge this is the first case of its kind that has been reported in the literature. After this event, personal communication has revealed that other institutions have had similar problems with the inlet cannulas, which subsequently resulted in a design change and voluntary recall of the inlet assembly by TCI.

A patient who has periodic or persistent bleeding at any time after implantation should be treated with the utmost caution; however, as the time after implantation increases, bleeding is less likely to be a function of surgical technique. The initial management of these patients should be centered on aggressive resuscitation, including transfusion as necessary, and correction of any aberrations in coagulation factors. Early angiographic evaluation is warranted to avoid progressive problems with these patients. Angiography should reveal any large breaks in the integrity of the pumping system.

A diagnostic angiogram, a nondiagnostic study with persistent evidence of bleeding, or a patient whose condition is too unstable to tolerate angiographic evaluation warrants immediate operative exploration. However, all care must be taken to control the device during the evaluation to prevent potential entrainment of air within the system, as has been previously described for explantation of these devices at the time of transplantation. ${ }^{3}$ These patients are dependent on augmented flow from these devices to sustain adequate perfusion. Hence weaning from the device before exploration is not a feasible option in most patients. The safest approach appears to be aggressive intervention by initiation of femoral-femoral cardiopulmonary bypass, thus allowing cessation of LVAD pumping before wide exploration of the circuit, anastomotic sites, and pockets. Any necessary interventions including complete pump replacement may then be undertaken while the patient is maintained with cardiopulmonary bypass.

Although this intervention may appear excessive for an unclear cause of bleeding, our case demonstrates that these patients may have significant problems with circuit continuity of the LVAD without manifesting significant clinical symptoms. Therefore we believe that early and aggressive management is warranted, because the consequences of exploration can prove devastating.

\section{REFERENCES}

1. McCarthy PM, Wang N, Vargo R. Preperitoneal insertion of the Heartmate 1000 IP implantable left ventricular assist device. Ann Thorac Surg 1994;57:634-8.

2. Radovancevic B, Frazier OH, Duncan JM. Implantation technique for the Heartmate left ventricular assist device. J Card Surg 1992; 7:203-7.

3. $\mathrm{Oz} \mathrm{MC}$, Levin HR, Rose EA. Technique for removal of left ventricular assist devices. Ann Thorac Surg 1994;58:257-8. 